Article

\title{
Toward a State-of-the-Art of Fly-Rock Prediction Technology in Open-Pit Mines Using EANNs Model
}

\author{
Hoang Nguyen ${ }^{1}\left(\mathbb{D}\right.$, Xuan-Nam Bui $^{2,3}$, Trung Nguyen-Thoi ${ }^{4,5, *(\mathbb{D}}$, Prashanth Ragam ${ }^{6}(\mathbb{D}$ and \\ Hossein Moayedi ${ }^{7}$ \\ 1 Institute of Research and Development, Duy Tan University, Da Nang 550000, Vietnam; \\ nguyenhoang23@duytan.edu.vn \\ 2 Department of Surface Mining, Mining Faculty, Hanoi University of Mining and Geology, 18 Vien st., \\ Duc Thang ward, Bac Tu Liem dist., Hanoi 100000, Vietnam; buixuannam@humg.edu.vn \\ 3 Center for Mining, Electro-Mechanical research, Hanoi University of Mining and Geology, 18 Vien st., \\ Duc Thang ward, Bac Tu Liem dist., Hanoi 100000, Vietnam \\ 4 Division of Computational Mathematics and Engineering, Institute for Computational Science, \\ Ton Duc Thang University, Ho Chi Minh City 700000, Vietnam \\ 5 Faculty of Civil Engineering, Ton Duc Thang University, Ho Chi Minh City 700000, Vietnam \\ 6 Department of Mining Engineering, NIT, Rourkela 769008, India; prashanth.rajam429@gmail.com \\ 7 Centre of Tropical Geoengineering (Geotropik), School of Civil Engineering, Faculty of Engineering, \\ Universiti Teknologi Malaysia, Johor Bahru 81310, Malaysia; hossein.moayedi@gmail.com \\ * Correspondence: nguyenthoitrung@tdtu.edu.vn
}

Received: 4 September 2019; Accepted: 21 October 2019; Published: 27 October 2019

\begin{abstract}
Fly-rock induced by blasting is an undesirable phenomenon in quarries. It can be dangerous for humans, equipment, and buildings. To minimize its undesirable hazards, we proposed a state-of-the-art technology of fly-rock prediction based on artificial neural network (ANN) models and their robust combination, called EANNs model (ensemble of ANN models); 210 fly-rock events were recorded to develop and test the ANN and EANNs models. Of thi sample, $80 \%$ of the whole dataset was assigned to develop the models, the remaining 20\% was assigned to confirm the models developed. Accordingly, five ANN models were designed and developed using the training dataset (i.e., $80 \%$ of the whole original data) first; then, their predictions on the training dataset were ensembled to generate a new training dataset. Subsequently, another ANN model was developed based on the new set of training data (i.e., EANNs model). Its performance was evaluated through a variety of performance indices, such as MAE (mean absolute error), MAPE (mean absolute percentage error), RMSE (root-mean-square error), $\mathrm{R}^{2}$ (correlation coefficient), and VAF (variance accounted for). A promising result was found for the proposed EANNs model in predicting blast-induced fly-rock with a MAE $=2.777, \mathrm{MAPE}=0.017, \mathrm{RMSE}=4.346, \mathrm{R}^{2}=0.986$, and $\mathrm{VAF}=98.446 \%$. To confirm the performance of the proposed EANNs model, another ANN model with the same structure was developed and tested on the training and testing datasets. The findings also indicated that the proposed EANNs model yielded better performance than those of the ANN model with the same structure.
\end{abstract}

Keywords: mining; fly-rock; ANN; EANNs; ensemble technique; bench blasting; artificial intelligence

\section{Introduction}

Fly-rock induced by blasting is a particular concern of engineers and mining enterprises. Although the blasting techniques have been improved, there are still many hazards produced by blasting operations, especially fly-rock [1-3]. It is considered as one of the prime causes of explosion-related accidents on open-cast mines [4-6]. In fact, estimating the distance of fly-rock was proposed very 
early based on experimental techniques (e.g., [7-9]). However, due to improper energy use factors of explosives, such as improper stemming, excessive powder factor, inadequate burden, unfavorable geological conditions, to name a few, the uncontrolled rocks are still propelled beyond the security area [10-12]. Therefore, empirical techniques were unable to explain the relationship between fly-rock and influencing factors adequately, and were uncontrollable in predicting whether blast-induced fly-rock was unavoidable.

To overcome the limitations of empirical methods, data-mining techniques were studied and applied by many scientists for predicting fly-rock in blasting operations. Its effectiveness has been proven not only in fly-rock forecasts but also in general technical issues [11-31]. For estimating the distance of fly-rock, Monjezi et al. [32] used a branch of artificial intelligence (AI), namely ANN (artificial neural network), based on the blasting parameters (i.e., powder factor, the diameter of borehole, blast ability index, stemming length, and a charge per delay). Finally, the charge per delay was defined as the most critical factor for reducing fly-rock. Similar works using the ANN technique for predicting fly-rock were also conducted by Ghasemi et al. [33], and Trivedi et al. [34]. Another machine-learning algorithm of AI, namely SVM (support vector machine), was also applied to predict the fly-rock distance by [35], Manoj, Monjezi [36]. ANFIS (adaptive neuro-fuzzy inference system) was also an AI technique that has been successfully applied by Trivedi et al. [37], for predicting the fly-rock distance with an excellent result.

However, conventional AI techniques do not seem to satisfy scientists. Therefore, Hasanipanah et al. [38] utilized an optimization algorithm, namely PSO (particle swarm optimization), for developing a robust equation for fly-rock prediction. Another meta-heuristic algorithm (i.e., differential evaluation algorithm-DE) was also used by Dehghani and Shafaghi [39] to combine with the dimensional analysis algorithm (DA) for estimating fly-rock distance. Its performance was confirmed by a variety of empirical techniques in their study. Based on the actions of fireflies, Faradonbeh et al. [40] also optimized blasting parameters to minimize the distance of fly-rock, using the firefly algorithm (FA). The genetic algorithm (GA) was also included to optimize the recurrent fuzzy neural network (RFNN), for predicting the fly-rock distance [41]. Under the optimal power of GA, an optimal RFNN model was established with a promising result in their study.

An overview of the related works indicated that many AI techniques had been developed to predict the fly-rock distance. However, they have not been confirmed in different areas with different geological conditions. Furthermore, new methods/models are always the targets of research by scientists aiming to improve the accuracy of the previous forecast models, minimizing the risks posed by fly-rock. Therefore, we proposed a state-of-the-art technology of fly-rock prediction based on ANN models and their robust combination, namely EANNs (ensemble of ANN models).

\section{Dataset Used}

This study was undertaken at a quarry mine in Vietnam, where the distance from residential was about $450-500 \mathrm{~m}$ (Figure 1). Herein, blasting was used as the primary technique for rock fragmentation using $75 \mathrm{~mm}$ of the borehole. Although many solutions have been proposed to minimize the distance of fly-rock; however, there are still many potential risks of unsafe activity due to fly-rock.

In order to investigate the causes, as well as the distance of fly-rock, we collected the basic parameters of 210 blasting events, including explosive charge per delay, powder factor, stemming, spacing, burden, and fly-rock distance, abbreviated as $\mathrm{W}, \mathrm{PF}, \mathrm{ST}, \mathrm{S}, \mathrm{B}$, and FR, respectively. These parameters were also used for estimating FR by many previous scientists (e.g., [10,42-44]). Subsequently, the experimental datasets were analyzed and visualized.

To measure the distance of FR in this study, the iGeoTrans app was installed on an iPhone Xs Max, as shown in Figure 2. This app can work on iOS devices, which is a product of Hanoi University of Mining and Geology (HUMG), Hanoi, Vietnam [45]. iGeoTrans used a GPS (Global Positioning System) to mark the positions of blast points and the maximum distance of FR in this study. The remaining parameters (input parameters) were extracted from the blast patterns in blasting design, such as W, 
PF, ST, S, and B. Table 1 lists the properties of the dataset used in this research. Besides, a matrix of the characteristics of the FR database was established, as shown in Figure 3. In which "Corr" was abbreviated as "Correlation."

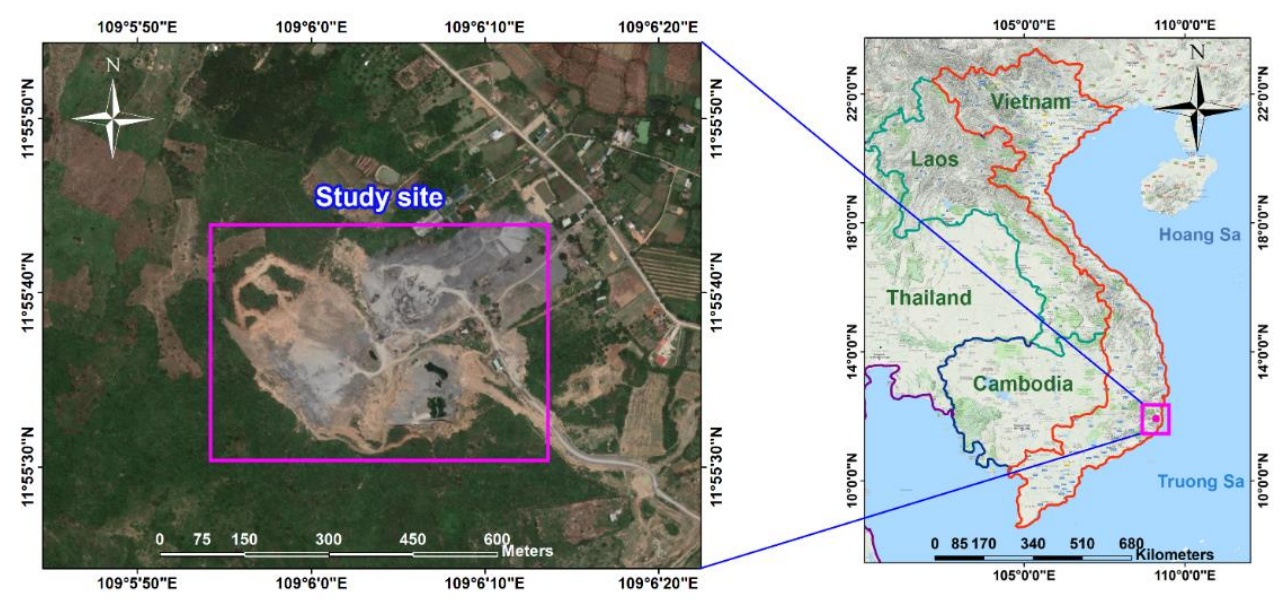

Figure 1. Location and overview of the study site.
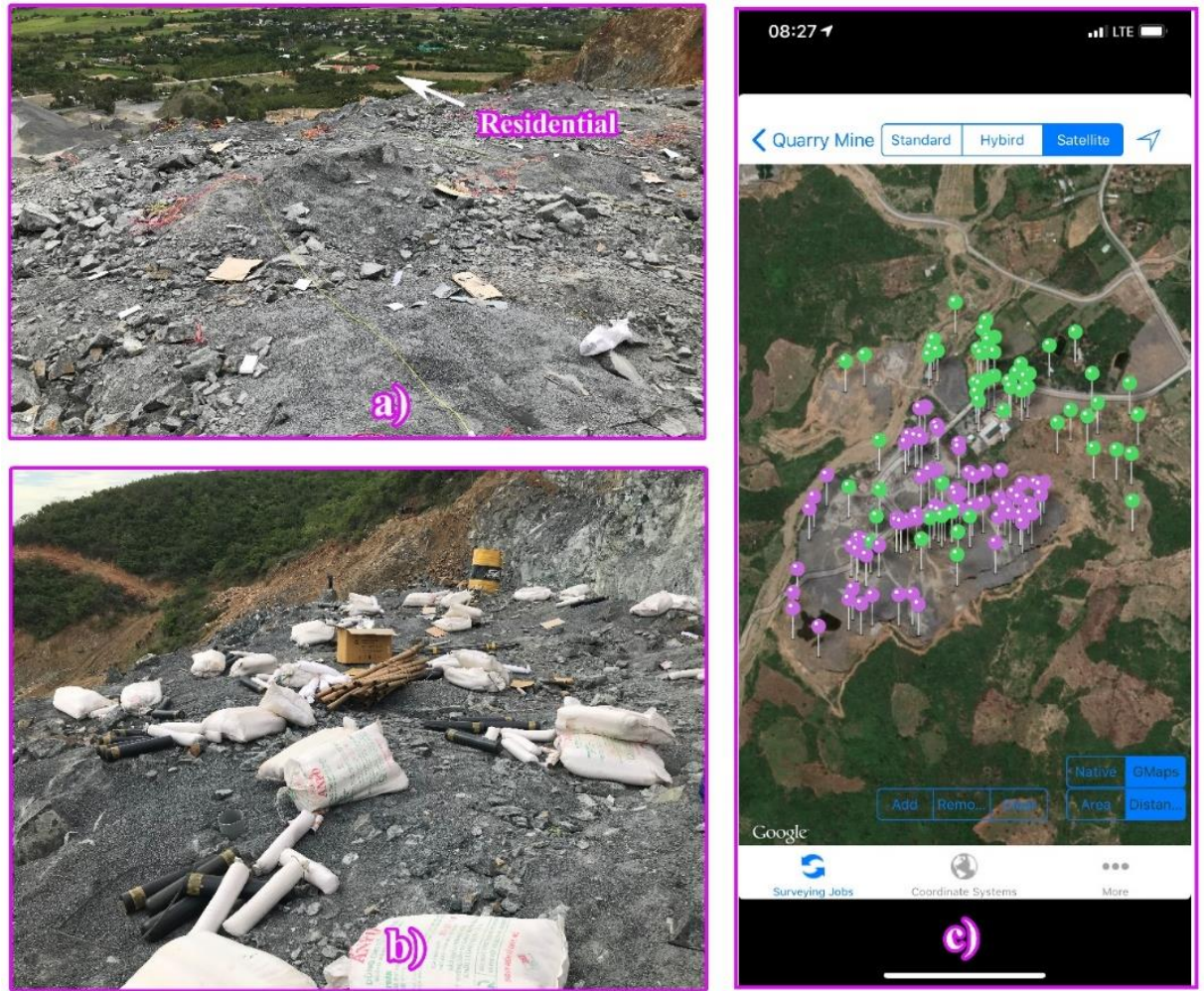

Figure 2. (a) Blast points; (b) ANFO explosive (ammonium nitrate/fuel oil); (c) iGeoTrans app with the monitoring points.

Table 1. Details of the parameters of blasting work in this study.

\begin{tabular}{ccccccc}
\hline & $\mathbf{B}(\mathbf{m})$ & $\mathbf{S}(\mathbf{m})$ & $\mathbf{S T}(\mathbf{m})$ & $\mathbf{W}(\mathbf{K g})$ & $\mathbf{P F}\left(\mathbf{k g} / \mathbf{m}^{\mathbf{3}}\right)$ & FR (m) \\
\hline Minimum & 1.272 & 2.010 & 0.5194 & 166.3 & 0.2578 & 101.1 \\
Mean & 2.090 & 3.021 & 1.3038 & 1236.4 & 0.4013 & 167.7 \\
Maximum & 2.982 & 4.137 & 2.5236 & 2820.5 & 0.5963 & 290.1 \\
\hline
\end{tabular}




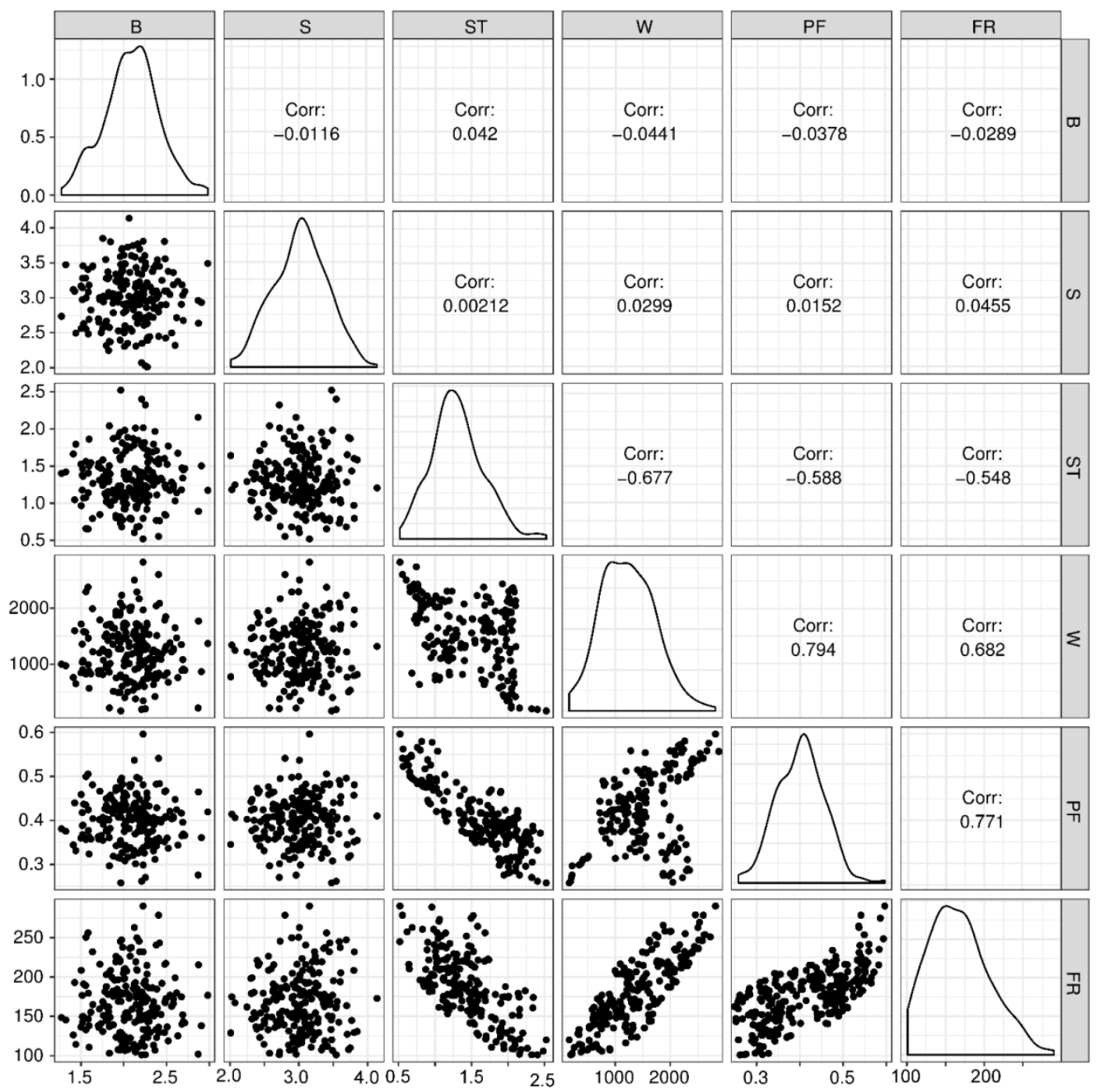

Figure 3. Matrix of the attributes used in the fly-rock database.

\section{Artificial Neural Network (ANN)}

Over the past few decades, the term "ANN" has become notable and has been adopted by a wide variety of applications, including atmospheric science, renewable energy systems, civil engineering $[46,47]$, microwave computer-aided design, medicine and treatment, and natural resources research [48-54]. It is a branch of the AI family inspired by human brain biological neurons. The underlying architecture of ANN consists of input layers, hidden layer(s), and an output layer [55-57]. Here, layers are developed by fundamental elements of ANN well known as many highly interconnected neurons (nodes or processing elements) along with activation function $[58,59]$. The primary purpose of the input layer is to communicate the output layer via the hidden layer(s) using weight values and activation function. Usually, the network's weights are adjusted (changes) and, accordingly, processed to obtain the desired response. Moreover, the ANN system with single hidden layer is adequate to compute the specified problem $[60,61]$. Whereas, ANN with two or more hidden layers pattern may create complex glitches [12]. The input elements (nodes) has been received the feature variables from raw environmental information and forwarded to the hidden layer. In this layer, it obtains knowledge of previous nodes and performs computations using encoded by weights and yield net input. Subsequently, the net input has been processed to the output layer through an activation function [62]. In the output layer, it has received the previous process information from the hidden layer(s) and computes the desired output with less error and more accurate. In the current study, the parameters include W, R, B, P, S, and FR and are considered as inputs and output, respectively. 
In ordered to predict blast-induced fly-rock efficiently, the following ANN architecture model was adopted and as depicted in Figure 4.

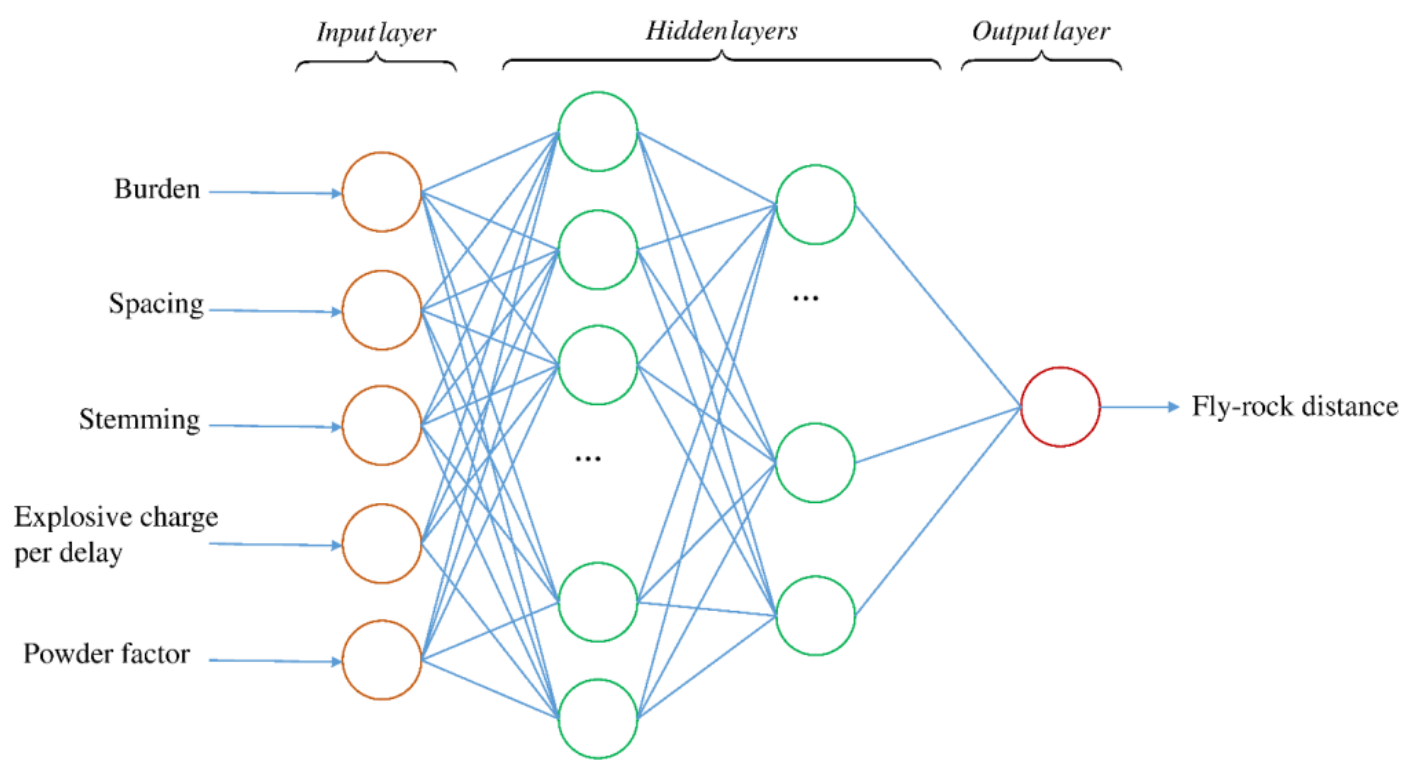

Figure 4. Artificial neural network (ANN) architecture for predicting blast-induced fly-rock efficiently.

\section{Combination of Multiple ANN Models}

The ensemble is well-known as a robust technique to improve the accuracy of the individual models [63]. Herein, a combination of multiple ANN models was conducted to solve the problem of fly-rock. In other words, five ANN models were jointed to create a new ANN model (called the EANNs model), for estimating FR herein. Note that the five ANN models were considered as the five independent models, and they must be developed first; then, a combination of the five developed ANN models was carried out. The framework of an ensemble of the ANN models is shown in Figure 5.

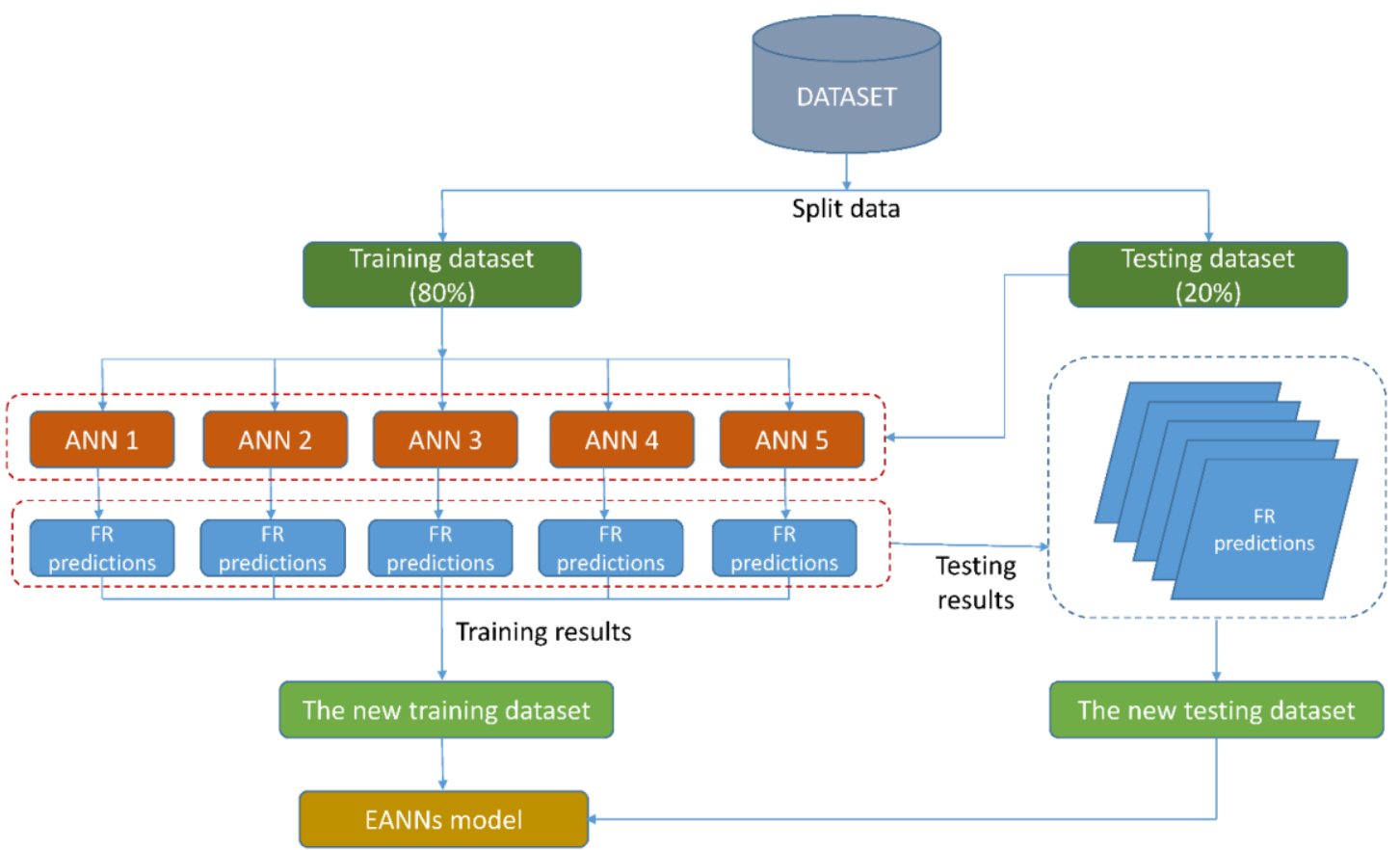

Figure 5. Context of the ANNs ensemble for estimating fly-rock distance (FR) in this work. 


\section{Performance Indexes for Evaluation of the Models}

For model evaluation, this study used five statistical indexes, including MAE (mean absolute error), MAPE (mean absolute percentage error), RMSE (root-mean-squared error), VAF (variance accounted for), and $R^{2}$ (correlation coefficient). They are computed as follow:

$$
\begin{aligned}
& \operatorname{MAE}=\frac{1}{n} \sum_{i=1}^{n}\left|y_{\text {flyrock }, i}-\hat{y}_{\text {flyrock }, i}\right|
\end{aligned}
$$

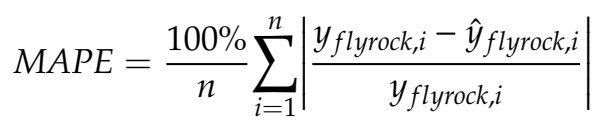

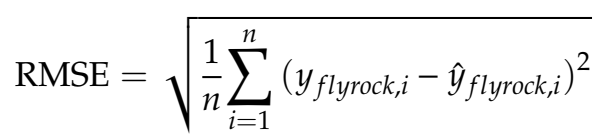

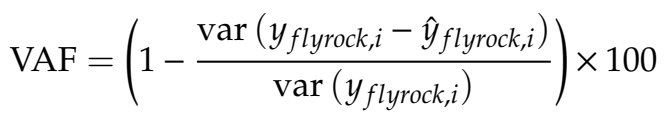

$$
\begin{aligned}
& \mathrm{R}^{2}=1-\frac{\sum_{i}\left(y_{\text {flyrock }, i}-\hat{y}_{\text {flyrock }, i}\right)^{2}}{\sum_{i}\left(y_{\text {flyrock }, i}-\bar{y}_{\text {flyrock }}\right)^{2}}
\end{aligned}
$$

where $y_{\text {flyrock, } i}$ is the $i^{\text {th }}$ of measured fly-rock; $\hat{y}_{\text {flyrock, } i}$ is the $i^{\text {th }}$ of predicted fly-rock; $\bar{y}_{\text {flyrock }}$ is mean of measured values of fly-rock distance; $n$ indicates number of observations in the training or testing datasets.

\section{Results}

Before developing the ANN and EANNs models for predicting FR, the original dataset was divided randomly into two parts: (1) training part ( $80 \%$ of the whole original database); (2) testing part (20\% remained).

As illustrated in Figure 5, five ANN models were developed first; then, they were combined as a new generation of ANN model (i.e., EANNs model). To avoid the over-fitting of the ANN models, the original dataset was normalized by a min-max scale in the range of $[-1,1]$. Finally, five ANN models were selected for predicting FR in the first step, including ANN 5-7-5-1, ANN 5-10-8-1, ANN 5-14-9-1, ANN 5-18-13-1, and ANN 5-21-16-1. An ANN model for predicting FR in this study is illustrated in Figure 6. Subsequently, an ensemble of the five developed ANN models was conducted (i.e., EANNs model). The structure of the proposed EANNs model is shown in Figure 7. Accordingly, the structure of the EANNs model includes three hidden layers (i.e., 5-25-21-15-1); therefore, to have a complete conclusion, the EANNs model was used to train and test the original data (called ANN 5-25-21-15-1 model). The results of the FR predictive models are computed in Tables 2 and 3.

Based on the statistical indexes in Tables 2 and 3, the ANN models (six sub-models) performed very well in estimating FR. Their performance is relatively uniform. Notably, the third sub-model (i.e., ANN 5-14-9-1) seems to provide the lowest performance among the six ANN models. For the proposed EANNs model, the high red intensity has revealed that its performance is superior in this study. It should be noted that the EANNs model was developed based on an ensemble of the first five ANN models in Tables 2 and 3, and the sixth ANN model was only developed based on the original database to compare with the EANNs model (with the new database based on the predictions of the first five ANN models). The promising results of the proposed EANNs model were validated through the statistical indexes in Tables 2 and 3. Remarkably, the sixth ANN model (i.e., ANN 5-25-21-15-1) has three hidden layers that have the same structure as those of the proposed EANNs model; however, its performance was lower than those of the proposed EANNs model. Thus, the use of the available 
ANN models as the sub-models to build a new model (i.e., EANNs model) has led to significant improvement in predicting FR. Figure 8 shows the accuracy of different ANN and EANNs models. Furthermore, a comparison of the proposed EANNs model (on the new database) and an ANN model with the same structure (on the original database) is shown in Figure 9.

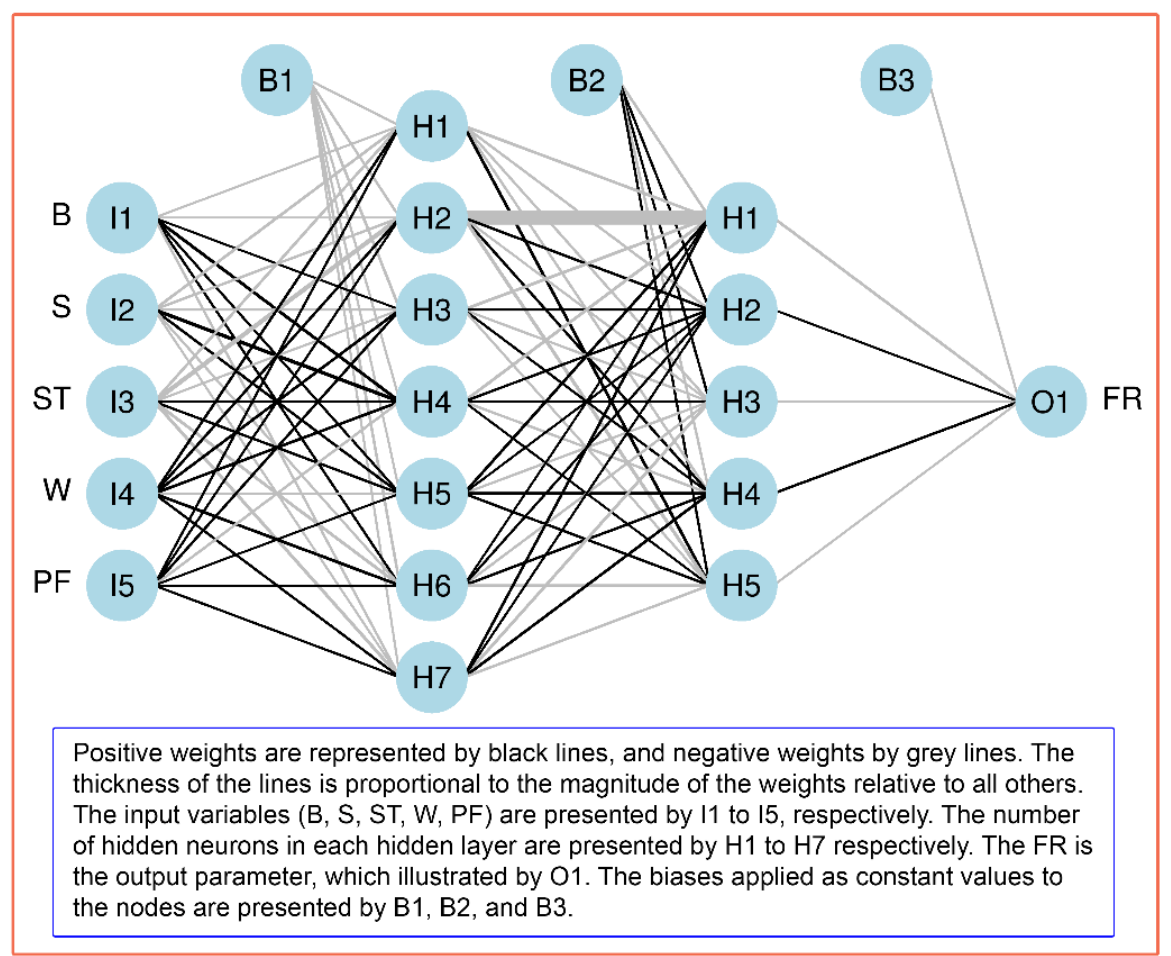

Figure 6. The ANN 5-7-5-1 model for estimating FR.

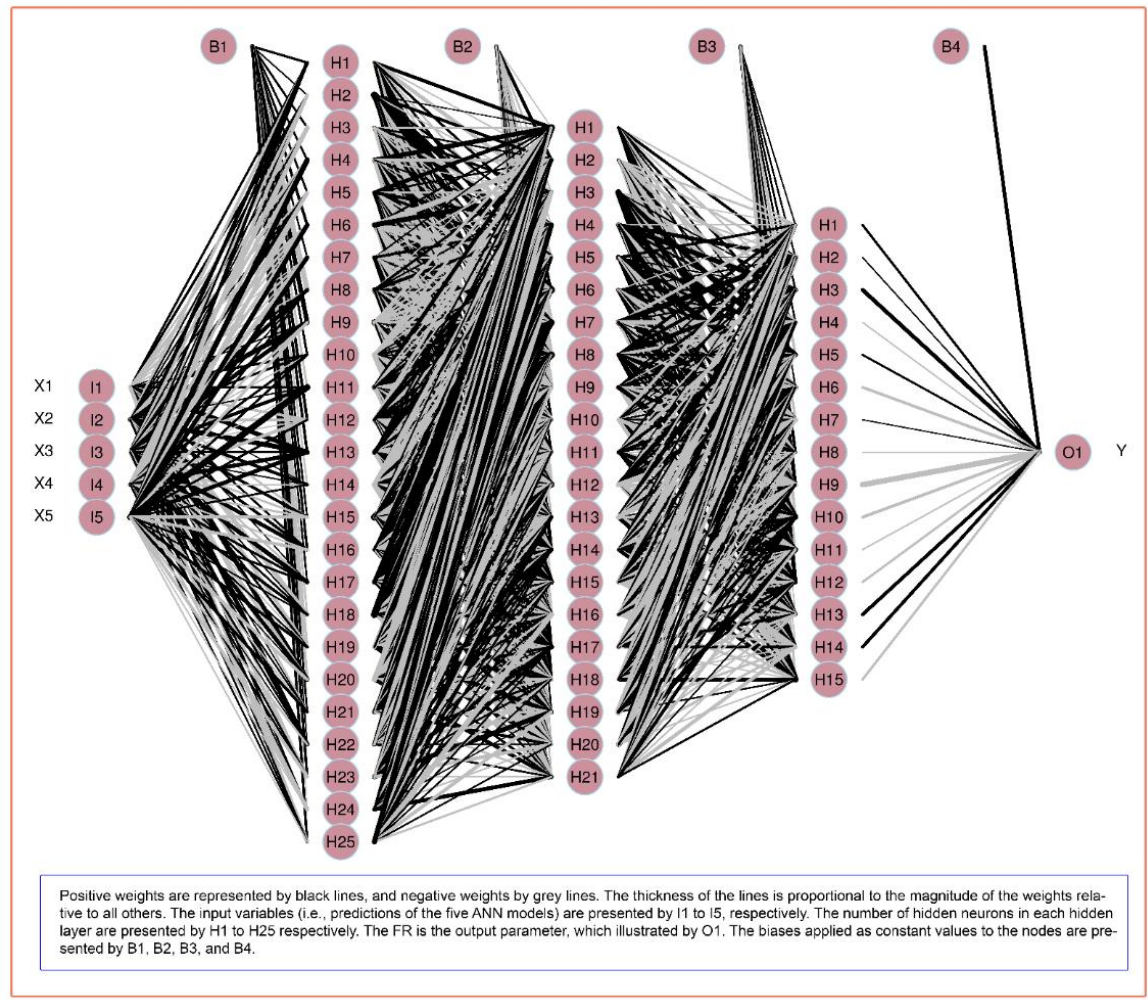

Figure 7. The proposed EANNs model (ensemble of the ANN models) for estimating FR. 
Table 2. Statistical indexes of the models for a set of data in the training.

\begin{tabular}{|c|c|c|c|c|c|c|c|c|c|c|}
\hline Model & MAE & MAPE & RMSE & VAF & $\mathbf{R}^{2}$ & Rank for MAE & Rank for MAPE & Rank for RMSE & Rank for VAF & Rank for $R^{2}$ \\
\hline $\begin{array}{c}\text { ANN } \\
5-7-5-1\end{array}$ & 3.301 & 0.021 & 6.231 & 97.563 & 0.976 & 6 & 5 & 5 & 5 & 5 \\
\hline $\begin{array}{l}\text { ANN } \\
5-10-8-1\end{array}$ & 3.416 & 0.022 & 6.413 & 97.419 & 0.974 & 4 & 4 & 2 & 2 & 2 \\
\hline $\begin{array}{l}\text { ANN } \\
5-14-9-1\end{array}$ & 3.326 & 0.021 & 6.122 & 97.648 & 0.976 & 5 & 5 & 6 & 6 & 5 \\
\hline $\begin{array}{c}\text { ANN } \\
5-18-13-1\end{array}$ & 3.482 & 0.023 & 6.309 & 97.502 & 0.975 & 3 & 3 & 4 & 4 & 3 \\
\hline $\begin{array}{l}\text { ANN } \\
5-21-16-1\end{array}$ & 3.67 & 0.024 & 6.672 & 97.206 & 0.972 & 2 & 1 & 1 & 1 & 1 \\
\hline $\begin{array}{l}\text { ANN } \\
5-25-21-1\end{array}$ & 3.695 & 0.024 & 6.361 & 97.460 & 0.975 & 1 & 1 & 3 & 3 & 3 \\
\hline EANNs & 2.908 & 0.019 & 4.954 & 98.464 & 0.985 & 7 & 7 & 7 & 7 & 7 \\
\hline
\end{tabular}

Note: MAE (mean absolute error), MAPE (mean absolute percentage error), RMSE (root-mean-squared error), VAF (variance accounted for), and $\mathrm{R}^{2}$ (correlation coefficient).

Table 3. Statistical indexes of the models for a set of data in the testing.

\begin{tabular}{|c|c|c|c|c|c|c|c|c|c|c|}
\hline Model & MAE & MAPE & RMSE & VAF & $\mathbf{R}^{2}$ & Rank for MAE & Rank for MAPE & Rank for RMSE & Rank for VAF & Rank for $R^{2}$ \\
\hline $\begin{array}{c}\text { ANN } \\
5-7-5-1\end{array}$ & 3.227 & 0.019 & 5.71 & 97.242 & 0.974 & 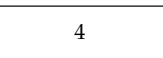 & 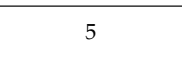 & 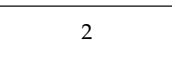 & 3 & 2 \\
\hline $\begin{array}{l}\text { ANN } \\
5-10-8-1\end{array}$ & 3.162 & 0.019 & 5.55 & 97.349 & 0.975 & 6 & 5 & 4 & 4 & 3 \\
\hline $\begin{array}{l}\text { ANN } \\
5-14-9-1\end{array}$ & 3.202 & 0.02 & 5.684 & 97.225 & 0.975 & 5 & 4 & 3 & 2 & 3 \\
\hline $\begin{array}{c}\text { ANN } \\
5-18-13-1\end{array}$ & 3.322 & 0.021 & 5.459 & 97.437 & 0.975 & 2 & 2 & 6 & 6 & 3 \\
\hline $\begin{array}{c}\text { ANN } \\
5-21-16-1\end{array}$ & 3.300 & 0.021 & 5.945 & 96.919 & 0.973 & 3 & 2 & 1 & 1 & 1 \\
\hline $\begin{array}{c}\text { ANN } \\
5-25-21-1\end{array}$ & 3.568 & 0.022 & 5.541 & 97.373 & 0.975 & 1 & 1 & 5 & 5 & 3 \\
\hline EANNs & 2.777 & 0.017 & 4.346 & 98.446 & 0.986 & 7 & 7 & 7 & 7 & 7 \\
\hline
\end{tabular}
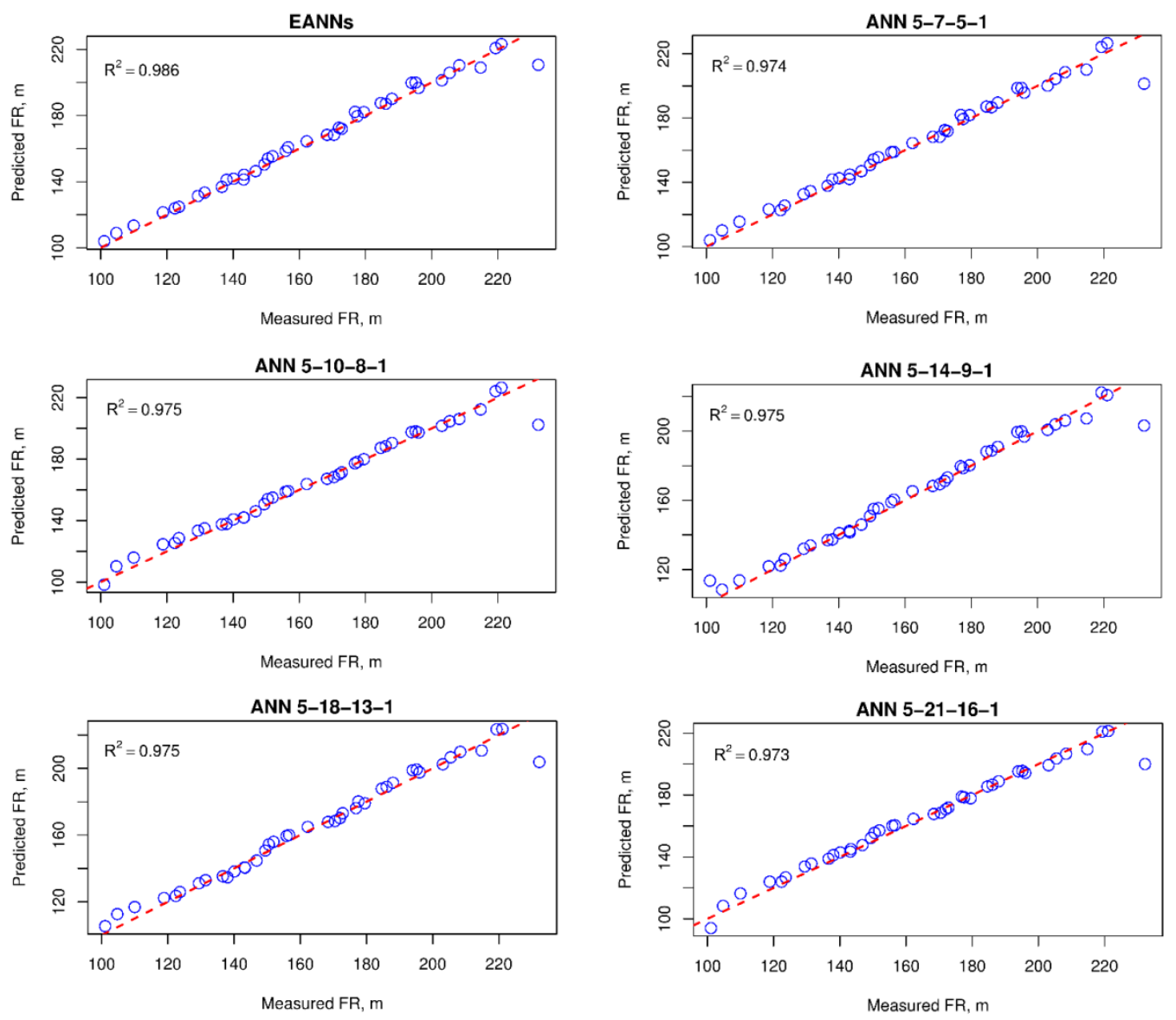

Figure 8. Accuracy of different ANN and EANNs models in estimating fly-rock. 

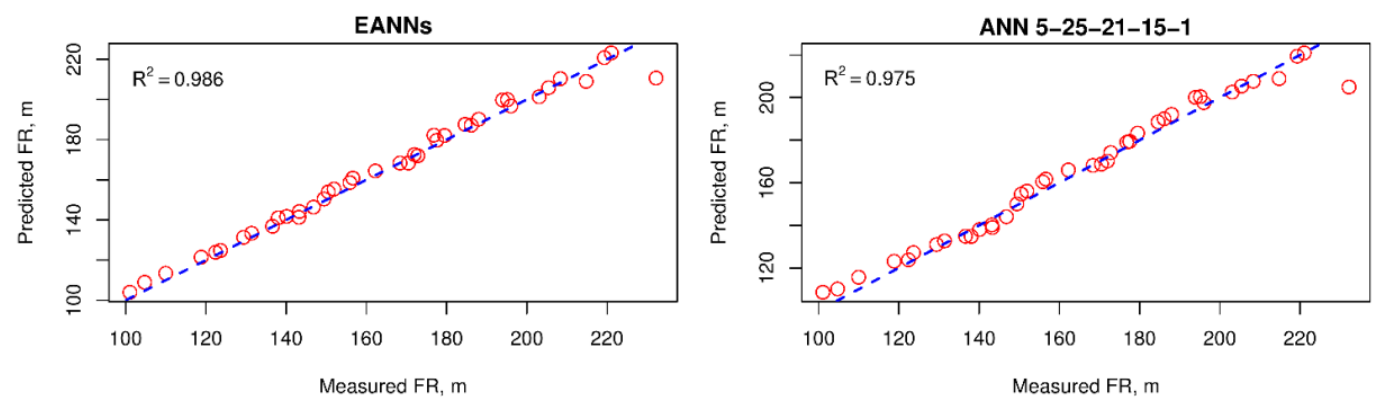

Figure 9. Comparison of the proposed EANNs and ANN models with the same structure.

Although the EANNs' performance is outstanding; however, the effects of the input parameters need to be taken into account to evaluate the importance of the inputs for predicting FR. Accordingly, the sensitivity of the input parameters was analyzed, as shown in Figure 10. Eventually, ST and W were found to have the most effect on the training of the proposed EANNs model, whereas the remaining parameters (i.e., PF, S, B) also affect the model, but not much.

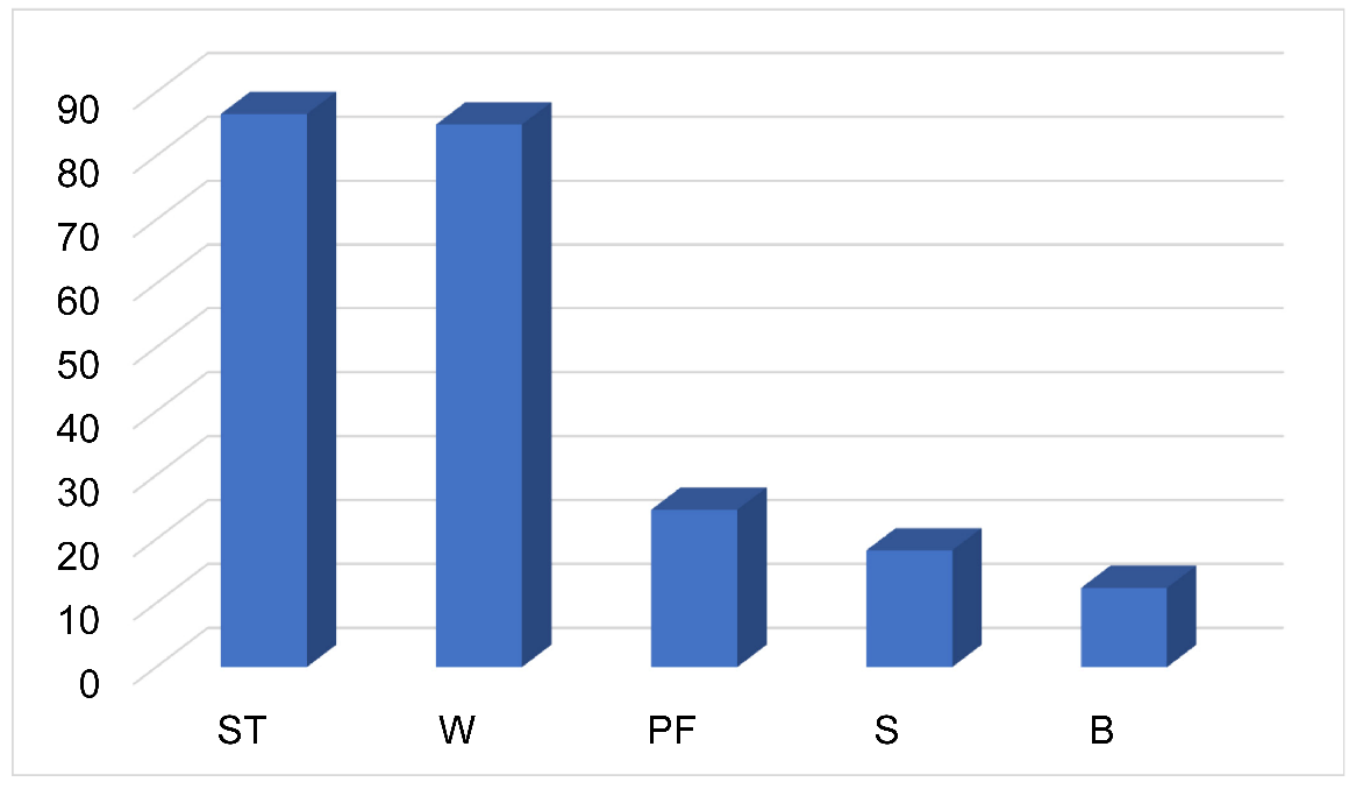

Figure 10. Sensitivity analysis results for input parameters.

\section{Conclusions}

Fly-rock is an undesirable phenomenon that is generated by mine blasting. It is evaluated as the most dangerous phenomenon among the side effects of blasting. This study introduced a state-of-the-art technology of fly-rock prediction with high accuracy based on ANN models and their robust combination (i.e., EANNs). The findings indicated that the proposed EANNs' performance was improved significantly when compared to the sub-models (i.e., ANN models). In other words, individual ANN models have served as positive input variables to improve the accuracy of the proposed EANNs model. This finding is impressive, and it should be applied in experimental conditions to control the distance of fly-rock, reducing the risks to humans and equipment.

Author Contributions: Data collection and experimental works: H.N., X.-N.B.; Writing, discussion, analysis: H.N., X.-N.B., H.M., P.R.; Revise and preparing the revision: H.N., X.-N.B., T.N.-T.

Funding: This research received no external funding.

Acknowledgments: The authors would like to thank Hanoi University of Mining and Geology (HUMG), Hanoi, Vietnam; Duy Tan University, Da Nang, Vietnam; and the Center for Mining, Electro-Mechanical research of HUMG. 
Conflicts of Interest: The authors declare no conflict of interest.

\section{References}

1. Kecojevic, V.; Radomsky, M. Flyrock phenomena and area security in blasting-related accidents. Saf. Sci. 2005, 43, 739-750. [CrossRef]

2. Bui, X.-N.; Jaroonpattanapong, P.; Nguyen, H.; Tran, Q.-H.; Long, N.Q. A novel Hybrid Model for predicting Blast-induced Ground Vibration Based on k-nearest neighbors and particle Swarm optimization. Sci. Rep. 2019, 9, 13971. [CrossRef] [PubMed]

3. Choi, Y.; Song, J. Review of photovoltaic and wind power systems utilized in the mining industry. Renew. Sustain. Energy Rev. 2017, 75, 1386-1391. [CrossRef]

4. Verakis, H.; Lobb, T. Blasting accidents in surface mines, a two decade summary. In Proceedings of the Annual Conference on Explosives and Blasting Technique; International Society of Explosives Engineers: Cleveland, OH, USA, 28-31 January 2001; Volume I, pp. 145-152.

5. Choi, Y.; Park, H.-D.; Sunwoo, C. Flood and gully erosion problems at the Pasir open pit coal mine, Indonesia: A case study of the hydrology using GIS. Bull. Eng. Geol. Environ. 2008, 67, 251-258. [CrossRef]

6. Choi, Y. A new algorithm to calculate weighted flow-accumulation from a DEM by considering surface and underground stormwater infrastructure. Environ. Model. Softw. 2012, 30, 81-91. [CrossRef]

7. Langefors, U.; Kihlström, B. The Modern Technique of Rock Blasting; Wiley: Hoboken, NJ, USA, 1963.

8. Roth, J. A Model for the Determination of Flyrock Range as a Function of Shot Conditions; US Bureau of Mines Contract JManagement Science Associates: Los Altos, CA, USA, 1979.

9. Lundborg, N. Risk for Flyrock when Blasting; BFR Report R; Swedish Council for Building Research: Stockholm, Sweden, 1981; Volume 29.

10. Monjezi, M.; Khoshalan, H.A.; Varjani, A.Y. Prediction of flyrock and backbreak in open pit blasting operation: A neuro-genetic approach. Arab. J. Geosci. 2012, 5, 441-448. [CrossRef]

11. Nguyen, H.; Bui, X.-N.; Bui, H.-B.; Cuong, D.T. Developing an XGBoost model to predict blast-induced peak particle velocity in an open-pit mine: A case study. Acta Geophys. 2019, 67, 477-490. [CrossRef]

12. Nguyen, H.; Bui, X.-N.; Bui, H.-B.; Mai, N.-L. A comparative study of artificial neural networks in predicting blast-induced air-blast overpressure at Deo Nai open-pit coal mine, Vietnam. Neural Comput. Appl. 2018, 1-17. [CrossRef]

13. Bui, X.N.; Nguyen, H.; Le, H.A.; Bui, H.B.; Do, N.H. Prediction of Blast-induced Air Over-pressure in Open-Pit Mine: Assessment of Different Artificial Intelligence Techniques. Nat. Resour. Res. 2019. [CrossRef]

14. Le, L.T.; Nguyen, H.; Dou, J.; Zhou, J. A Comparative Study of PSO-ANN, GA-ANN, ICA-ANN, and ABC-ANN in Estimating the Heating Load of Buildings' Energy Efficiency for Smart City Planning. Appl. Sci. 2019, 9, 2630. [CrossRef]

15. Khandelwal, M.; Singh, T. Prediction of blast-induced ground vibration using artificial neural network. Int. J. Rock Mech. Min. Sci. 2009, 46, 1214-1222. [CrossRef]

16. Zhou, J.; Shi, X.-Z.; Huang, R.-D.; Qiu, X.-Y.; Chong, C. Feasibility of stochastic gradient boosting approach for predicting rockburst damage in burst-prone mines. Trans. Nonferrous Met. Soc. China 2016, 26, 1938-1945. [CrossRef]

17. Hasanipanah, M.; Shahnazar, A.; Amnieh, H.B.; Armaghani, D.J. Prediction of air-overpressure caused by mine blasting using a new hybrid PSO-SVR model. Eng. Comput. 2017, 33, 23-31. [CrossRef]

18. Hajihassani, M.; Armaghani, D.J.; Marto, A.; Mohamad, E.T. Ground vibration prediction in quarry blasting through an artificial neural network optimized by imperialist competitive algorithm. Bull. Eng. Geol. Environ. 2015, 74, 873-886. [CrossRef]

19. Ghasemi, E.; Kalhori, H.; Bagherpour, R. A new hybrid ANFIS-PSO model for prediction of peak particle velocity due to bench blasting. Eng. Comput. 2016, 32, 607-614. [CrossRef]

20. Gao, W.; Karbasi, M.; Hasanipanah, M.; Zhang, X.; Guo, J. Developing GPR model for forecasting the rock fragmentation in surface mines. Eng. Comput. 2018, 34, 339-345. [CrossRef]

21. Carranza, E.J.M. Data-Driven Evidential Belief Modeling of Mineral Potential Using Few Prospects and Evidence with Missing Values. Nat. Resour. Res. 2015, 24, 291-304. [CrossRef]

22. Bui, X.N.; Muazu, M.A.; Nguyen, H. Optimizing Levenberg-Marquardt backpropagation technique in predicting factor of safety of slopes after two-dimensional OptumG2 analysis. Eng. Comput. 2019. [CrossRef] 
23. Asteris, P.G.; Argyropoulos, I.; Cavaleri, L.; Rodrigues, H.; Varum, H.; Thomas, J.; Lourenço, P.B. Masonry Compressive Strength Prediction using Artificial Neural Networks. In International Conference on Transdisciplinary Multispectral Modeling and Cooperation for the Preservation of Cultural Heritage; Springer: Cham, Switzerland, 2018; pp. 200-224.

24. Armaghani, D.J.; Mohamad, E.T.; Narayanasamy, M.S.; Narita, N.; Yagiz, S. Development of hybrid intelligent models for predicting TBM penetration rate in hard rock condition. Tunn. Undergr. Space Technol. 2017, 63, 29-43. [CrossRef]

25. Dou, J.; Paudel, U.; Oguchi, T.; Uchiyama, S.; Hayakavva, Y.S. Shallow and Deep-Seated Landslide Differentiation Using Support Vector Machines: A Case Study of the Chuetsu Area, Japan. Terr. Atmos. Ocean. Sci. 2015, 26, 227-239. [CrossRef]

26. Prashanth, R.; Nimaje, D. Estimation of ambiguous blast-induced ground vibration using intelligent models: A case study. Noise Vib. Worldw. 2018, 49, 147-157. [CrossRef]

27. Taheri, K.; Hasanipanah, M.; Golzar, S.B.; Majid, M.Z.A. A hybrid artificial bee colony algorithm-artificial neural network for forecasting the blast-produced ground vibration. Eng. Comput. 2017, 33, 689-700. [CrossRef]

28. Nguyen, H.; Bui, X.-N. Predicting Blast-Induced Air Overpressure: A Robust Artificial Intelligence System Based on Artificial Neural Networks and Random Forest. Nat. Resour. Res. 2018, 1-15. [CrossRef]

29. Nguyen, H.; Bui, X.-N.; Moayedi, H. A comparison of advanced computational models and experimental techniques in predicting blast-induced ground vibration in open-pit coal mine. Acta Geophys. 2019. [CrossRef]

30. Nguyen, H.; Bui, X.-N.; Tran, Q.-H.; Mai, N.-L. A new soft computing model for estimating and controlling blast-produced ground vibration based on hierarchical K-means clustering and cubist algorithms. Appl. Soft Comput. 2019, 77, 376-386. [CrossRef]

31. Luo, Z.; Bui, X.-N.; Nguyen, H.; Moayedi, H. A novel artificial intelligence technique for analyzing slope stability using PSO-CA model. Eng. Comput. 2019. [CrossRef]

32. Monjezi, M.; Bahrami, A.; Varjani, A.Y.; Sayadi, A.R. Prediction and controlling of flyrock in blasting operation using artificial neural network. Arab. J. Geosci. 2011, 4, 421-425. [CrossRef]

33. Ghasemi, E.; Amini, H.; Ataei, M.; Khalokakaei, R. Application of artificial intelligence techniques for predicting the flyrock distance caused by blasting operation. Arab. J. Geosci. 2014, 7, 193-202. [CrossRef]

34. Trivedi, R.; Singh, T.; Raina, A. Prediction of blast-induced flyrock in Indian limestone mines using neural networks. J. Rock Mech. Geotech. Eng. 2014, 6, 447-454. [CrossRef]

35. Amini, H.; Gholami, R.; Monjezi, M.; Torabi, S.R.; Zadhesh, J. Evaluation of flyrock phenomenon due to blasting operation by support vector machine. Neural Comput. Appl. 2012, 21, 2077-2085. [CrossRef]

36. Manoj, K.; Monjezi, M. Prediction of flyrock in open pit blasting operation using machine learning method. Int. J. Min. Sci. Technol. 2013, 23, 313-316. [CrossRef]

37. Trivedi, R.; Singh, T.; Gupta, N. Prediction of blast-induced flyrock in opencast mines using ANN and ANFIS. Geotech. Geol. Eng. 2015, 33, 875-891. [CrossRef]

38. Hasanipanah, M.; Armaghani, D.J.; Amnieh, H.B.; Majid, M.Z.A.; Tahir, M.M. Application of PSO to develop a powerful equation for prediction of flyrock due to blasting. Neural Comput. Appl. 2017, 28, 1043-1050. [CrossRef]

39. Dehghani, H.; Shafaghi, M. Prediction of blast-induced flyrock using differential evolution algorithm. Eng. Comput. 2017, 33, 149-158. [CrossRef]

40. Faradonbeh, R.S.; Armaghani, D.J.; Amnieh, H.B.; Mohamad, E.T. Prediction and minimization of blast-induced flyrock using gene expression programming and firefly algorithm. Neural Comput. Appl. 2018, 29, 269-281. [CrossRef]

41. Rad, H.N.; Bakhshayeshi, I.; Jusoh, W.A.W.; Tahir, M.; Foong, L.K. Prediction of Flyrock in mine blasting: A new computational intelligence approach. Nat. Resour. Res. 2019, 1-15. [CrossRef]

42. Armaghani, D.J.; Hajihassani, M.; Mohamad, E.T.; Marto, A.; Noorani, S. Blasting-induced flyrock and ground vibration prediction through an expert artificial neural network based on particle swarm optimization. Arab. J. Geosci. 2014, 7, 5383-5396. [CrossRef]

43. Hasanipanah, M.; Faradonbeh, R.S.; Armaghani, D.J.; Amnieh, H.B.; Khandelwal, M. Development of a precise model for prediction of blast-induced flyrock using regression tree technique. Environ. Earth Sci. 2017, 76, 27. [CrossRef] 
44. Kumar, N.; Mishra, B.; Bali, V. A Novel Approach for Blast-Induced Fly Rock Prediction Based on Particle Swarm Optimization and Artificial Neural Network. In Proceedings of International Conference on Recent Advancement on Computer and Communication; Springer: Singapore, 2018; pp. 19-27.

45. Guo, H.; Nguyen, H.; Bui, X.-N.; Armaghani, D.J. A new technique to predict fly-rock in bench blasting based on an ensemble of support vector regression and GLMNET. Eng. Comput. 2019. [CrossRef]

46. Asteris, P.; Kolovos, K.; Douvika, M.; Roinos, K. Prediction of self-compacting concrete strength using artificial neural networks. Eur. J. Environ. Civ. Eng. 2016, 20 (Suppl. 1), s102-s122. [CrossRef]

47. Asteris, P.G.; Nikoo, M. Artificial bee colony-based neural network for the prediction of the fundamental period of infilled frame structures. Neural Comput. Appl. 2019. [CrossRef]

48. Gardner, M.W.; Dorling, S. Artificial neural networks (the multilayer perceptron)—A review of applications in the atmospheric sciences. Atmos. Environ. 1998, 32, 2627-2636. [CrossRef]

49. Kalogirou, S.A. Artificial neural networks in renewable energy systems applications: A review. Renew. Sustain. Energy Rev. 2001, 5, 373-401. [CrossRef]

50. Gao, W.; Wang, W.; Dimitrov, D.; Wang, Y. Nano properties analysis via fourth multiplicative ABC indicator calculating. Arab. J. Chem. 2018, 11, 793-801. [CrossRef]

51. Moayed, H.; Rashid, A.S.A.; Muazu, M.A.; Nguyen, H.; Bui, X.-N.; Bui, D.T. Prediction of ultimate bearing capacity through various novel evolutionary and neural network models. Eng. Comput. 2019. [CrossRef]

52. Burrascano, P.; Fiori, S.; Mongiardo, M. A review of artificial neural networks applications in microwave computer-aided design (invited article). Int. J. RF Microw. Comput. Aided Eng. 1999, 9, 158-174. [CrossRef]

53. Lisboa, P.J.; Taktak, A.F. The use of artificial neural networks in decision support in cancer: A systematic review. Neural Netw. 2006, 19, 408-415. [CrossRef]

54. Carranza, E.J.M. Natural resources research publications on geochemical anomaly and mineral potential mapping, and introduction to the special issue of papers in these fields. Nat. Resour. Res. 2017, 26, 379-410. [CrossRef]

55. Yegnanarayana, B. Artificial Neural Networks; PHI Learning Pvt. Ltd.: New Delhi, India, 2009.

56. Nguyen, H.; Drebenstedt, C.; Bui, X.-N.; Bui, D.T. Prediction of Blast-Induced Ground Vibration in an Open-Pit Mine by a Novel Hybrid Model Based on Clustering and Artificial Neural Network. Nat. Resour. Res. 2019. [CrossRef]

57. Oh, H.-J.; Lee, S. Application of artificial neural network for gold-silver deposits potential mapping: A case study of Korea. Nat. Resour. Res. 2010, 19, 103-124. [CrossRef]

58. Buscema, P.M.; Massini, G.; Breda, M.; Lodwick, W.A.; Newman, F.; Asadi-Zeydabadi, M. Artificial Adaptive Systems Using Auto Contractive Maps: Theory, Applications and Extensions; Springer International Publishing AG: Cham, Switzerland, 2018.

59. Gao, W.; Guirao, J.L.G.; Abdel-Aty, M.; Xi, W. An independent set degree condition for fractional critical deleted graphs. Discret. Contin. Dyn. Syst. S 2018, 12, 877-886. [CrossRef]

60. Bui, D.T.; Tuan, T.A.; Klempe, H.; Pradhan, B.; Revhaug, I. Spatial prediction models for shallow landslide hazards: A comparative assessment of the efficacy of support vector machines, artificial neural networks, kernel logistic regression, and logistic model tree. Landslides 2016, 13, 361-378.

61. Zhang, X.; Nguyen, H.; Bui, X.-N.; Tran, Q.-H.; Nguyen, D.-A.; Bui, D.T.; Moayedi, H. Novel Soft Computing Model for Predicting Blast-Induced Ground Vibration in Open-Pit Mines Based on Particle Swarm Optimization and XGBoost. Nat. Resour. Res. 2019. [CrossRef]

62. Tessema, A. Mineral systems analysis and artificial neural network modeling of chromite prospectivity in the Western Limb of the Bushveld Complex, South Africa. Nat. Resour. Res. 2017, 26, 465-488. [CrossRef]

63. Zhou, Z.-H.; Wu, J.; Tang, W. Ensembling neural networks: Many could be better than all. Artif. Intell. 2002, 137, 239-263. [CrossRef]

(C) 2019 by the authors. Licensee MDPI, Basel, Switzerland. This article is an open access article distributed under the terms and conditions of the Creative Commons Attribution (CC BY) license (http://creativecommons.org/licenses/by/4.0/). 